\title{
JACQUES DERRIDA: ESPECTROS DE MARX. MÁS ALLÁ DE 'EL CAPITAL' Y EL FIN DE LA HISTORIA
}

\author{
Adolfo Vásquez Rocca ${ }^{1}$ \\ Pontificia Universidad Católica de Valparaíso \\ Universidad Complutense de Madrid
}

https://doi.org/10.33676/EMUI_nomads.55.10

\begin{abstract}
Resumen: En el presente artículo se discuten los alcances de la construcción de sentido, la deconstrucción en las fronteras de la Filosofía, así como las consecuencias estéticas y políticas de la noción de espectro, propuesta por Jacques Derrida en su libro de 1995 Espectros de Marx. La crítica que la introducción de la noción de espectro hace posible es tanto epistemológica como histórico-política. A continuación se analizan pasajes de "Noticias de la Antigüedad Ideológica Marx/Esenstein/El Capital" un desmesurado film de Alexander Kluge, de 2008, de más de 9 horas de duración y que gira en torno del proyecto irrealizado de Sergei Eisenstein de filmar "El Capital", de Karl Marx, no como un documental, sino como un relato construido con técnicas de flujo de conciencia tomadas del "Ulises" de Joyce.
\end{abstract}

Palabras clave: espectro, capital, marxismo, desconstrucción, performatividad, trabajo de duelo, micropolítica.

\section{Jacques Derrida: Spectros de Marx. Beyond 'The Capital' and the End of History}

Abstract: This article discusses the scope of the construction of meaning and the aesthetic and political consequences of the notion of spectrum, proposed by Jacques Derrida in his 1995 book Spectra by Marx. The criticism that the introduction of the notion of spectrum makes possible is both epistemological and historical-political. Below are analyzed passages from "News of the Ideological Antiquity - Marx / Esenstein / Capital", a disproportionate film by Alexander Kluge, from 2008, of more than 9 hours and which revolves around Sergei Eisenstein's unrealized project of filming "The Capitall", by Karl Marx, not as a documentary, but as a story constructed with techniques of consciousness flow taken from Joyce's "Ulysses".

Keywords: spectrum, capital, Marxism, deconstruction, performativity, bereavement work, micropolitics.

1 Doctor en Filosofía por la Pontificia Universidad Católica de Valparaíso; Postgrado Universidad Complutense de Madrid. Áreas de Especialización Antropología y Estética. Miembro de la Sociedad Española de Estética y Teoría de las Artes. Profesor de Postgrado del Instituto de Filosofía de la Pontificia Universidad Católica de Valparaíso. Profesor Adjunto Escuela de Psicología y de la Facultad de Arquitectura UNAB. Académico Investigador de la Vicerrectoría de Investigación y Postgrado, Universidad Andrés Bello. Consultor Experto del Consejo Nacional de Innovación para la Competitividad (CNIC) -Investigador Asociado y Profesor adjunto de la Escuela Matríztica de Santiago, Magíster en Biología-Cultural. Ha publicado entre otros el Libro: Peter Sloterdijk; Esferas, helada cósmica y políticas de climatización, Colección Novatores, No 28, Editorial de la Institución Alfons el Magnànim (IAM), Valencia, España, 2008. Invitado especial a la International Conference de la Trienal de Arquitectura de Lisboa 2016| Traducido al Francés - Publicado en la sección Architecture de la Anthologie: Le Néant Dans la Pensée Contemporaine. Publications du Centre Français d'Iconologie Comparée CFIC, (c) Bès Editions, París. E-Mail: adolfovrocca@gmail.com 


\section{I.- La Condición Posmoderna y la supuesta deslegitimación del marxismo.}

"Nachrichten aus der ideologischen Antike - Marx/Eisenstein/Das Kapital (Noticias de la Antigüedad Ideológica - Marx/Esenstein/El Capital) un desmesurado film de Alexander Kluge, de 2008, de más de 9 horas de duración y que gira en torno del proyecto irrealizado de Sergei Eisenstein (1898 - 1948) de filmar "El Capital", de Karl Marx, no como un documental, sino como un relato construido con técnicas de flujo de conciencia tomadas del "Ulises" de James Joyce, discuten los alcances de la construcción de sentido y las consecuencias estéticas y políticas de la noción de espectro, propuesta por Jacques Derrida 2 en su libro de 1995 Espectros de Marx. Espectros fue el primer título que Marx pensó para su Manifiesto. Derrida lo recupera en este libro como una especie de herencia de Marx. Derrida se muestra partidario de un cierto marxismo que contrarreste la imperante doctrina capitalista y que acalle las constantes e insistentes voces que, en un determinado espacio geopolítico, niegan la pervivencia del pensamiento de Marx y afirman su imposible recuperación.

Ahora bien, Espectros de Marx no es exactamente un libro sobre Marx; es una lectura de Marx en el contexto de la derrota de quienes se proclamaron y fueron aceptados como sus herederos, junto con el triunfo geopolítico de su enemigo, el liberalismo económico y político. Ante la caída de la Unión Soviética, una de las encarnaciones del espectro comunista, y el triunfo discutible, proclamado, entre otros, por Fukuyama, del pensamiento neoliberal, con su democracia y libre mercado, Derrida nos revela la actualidad de la lectura del texto de Marx. Espectros de Marx no es un libro sobre Marx, sino una lectura de Marx. Lectura que nos hace descubrir a un Marx más allá del estereotipo que inevitablemente se fue sedimentando entre quienes lo exaltaron $y$ lo repudiaron, pero que bien puede sospecharse que nunca lo leyeron.

En efecto, Marx, como Freud, sabía de la eficacia de los fantasmas, de los espíritus. La mercancía se convierte en fantasma en el momento que el que la produce ya no se encuentra reflejado en ella, en el momento en que le resulta extraña, ajena y él, el productor, se enajena.

En este sentido resulta apasionante la relectura de La ideología alemana y de El capital. La vigencia de entrevistas a Hans Magnus Enzensberger, Peter Sloterdijk, entre otros, rollos de imágenes, fotos, actas, pólvora y mapas.

La deconstrucción irrumpe en el pensamiento de la escritura, como una escritura de la escritura, que por lo pronto obliga a otra lectura: no ya imantada a la comprensión hermenéutica del sentido que quiere-decir

2 En noviembre de 1995, el profeta de la deconstrucción, Jacques Derrida, viajo a Santiago de Chile y sostuvo un debate público con especialistas en su obra. El acto fue organizado por Nelly Richard, directora de la Revista de Critica Cultural, que recogió en su número 12 las opiniones del autor de Espectros de Marx. 
un discurso, a su fondo de ilegibilidad y de deseo de idioma-, a las fuerzas no intencionales inscritas en los sistemas significantes de un discurso que hacen de éste propiamente un "texto", es decir, algo que por su propia naturaleza o por su propia ley se resiste a ser comprendido como expresión de un sentido, o más bien "expone" éste como efecto y con su legalidad y necesidad específica- de una ilusión para la conciencia.

Se interroga la noción con el fin de mostrar su fuerza crítica, por un lado y propositiva por otro. La crítica que la introducción de la noción de espectro hace posible es tanto epistemológica (interviniendo la clausura del concepto) como histórico-política (analizando el devenir contingente del sentido y no su historia lineal, reducida a pintar el escenario de su origen o su finalidad teleológica).

Así, tiene razón Derrida cuando defiende que "la deconstrucción nunca ha tenido ningún sentido o interés, a mi modo de ver, por lo menos, excepto como una radicalización, es decir también en la tradición de un cierto marxismo, en un cierto espíritu del marxismo". Aun cuando el mismo Marx creyó poder diferenciar tranquilamente entre espíritu (Geist) y espectro (Gespenst), espíritu verdadero de la revolución y sus fantasmas, realidad histórica e ilusión metafísica, la crítica marxiana señala siempre una operación escritural anterior, una traza incapturable por el sentido -por la historia, es decir por el valor de cambio-, por cuanto dicha traza inscribe las condiciones de posibilidad de todo sentido y de toda historia. Lógica suplementaria que se presenta, en Marx, bajo la resonancia enigmática de una figura: la división del trabajo.

Tentación, entonces -- pero no cedamos a ella sin ciertas precauciones - de traducir: el olvido del ser, el olvido de la pregunta por el ser, el olvido (constitutivo de la metafísica) de la diferencia entre ser y ente, no sería sino el borramiento originario de la división del trabajo, división que se instala ya de manera indisociable de su propio borramiento. Se habría inaugurado ahí el trabajo en el sentido metafísico -el único que conocemos: trabajo como olvido del trabajo (su división), trábajo del olvido y del duelo que, como se sabe desde Freud y Derrida, nunca ha sido un trabajo entre otros, sino la estructura fundamental, irreductible, del trabajo en cuanto tal. Todo trabajo es trabajo del duelo: duelo por nada menos que el borramiento originario de la división del trabajo. A partir de ahí la historia del presente sería inseparable de la historia de la catástrofe, la historia en tanto catástrofe (Benjamín dixit), catástrofe fundante de la historia en cuanto tal, historia que no puede sino desplegarse como olvido de la catástrofe que la funda. Por ello el pensamiento de Marx siempre ha sido antiapocalíptico - lo ha visto bien Derrida: la catástrofe ya ha ocurrido, la catástrofe no es sino el olvido cotidiano de la catástrofe fundante. ¿̇Vínculo constitutivo, entonces, entre historia y olvido ( $y$, por ende, entre trabajo y olvido)? No nos apresuremos. En estos términos, sin duda, la pregunta se halla mal 
puesta. Retomémosla a partir de la segunda posibilidad del titulo de Derrida, el genitivo subjetivo.

Pero la virtud del espectro es ir más allá de la crítica, abriendo un campo problemático ya regulado, como es el de la academia en humanidades, a lo excluido o impensado hasta entonces: nuevas proposiciones de sentido o aventuras de la diferencia.

Con La Condición Posmoderna ${ }^{3}$ Lyotard intenta dar cuenta de la deslegitimación del marxismo como ciencia y como programa de emancipación ubicándolo como uno de tos grandes relatos de la modernidad. En este caso el último relato de salvación que acaba de morir y que nadie quiere sustituirlo. El balance lo realiza sobre el resultado de las experiencias de los llamados "socialismos reales".

Entre los ex marxistas desilusionados, el tema postestructuralista del "fin de los grandes relatos" se puso tan de moda como la crítica al marxismo como "religión moderna".

El Capital, 4 la Summa de Marx, obra paradigmática en la que se ha desplegado como un singular acontecimiento político-epistémico, que durante siglo y medio ha abierto posibilidades para el pensamiento crítico, la praxis política y la imaginación emancipatoria. Hay un antes y un después de El capital.

Refiriéndose al Manifiesto, afirma Derrida, "Ningún texto de la tradición parece tan lúcido sobre la mundialización del curso de la política, sobre la irreductibilidad de la técnica y de la mediática". 5

A finales de los años 80 la revista liberal, Newsweek, anunciaba la muerte de Marx, que fue celebrada por Francis Fukuyama en El fin de la historia y el último hombreb, pero encumbrado por los poderes fácticos a un evangelio de los nuevos tiempos que anuncia el triunfo definitivo de la democracia liberal y el entierro oficial del marxismo. Sí un nuevo evangelio, el más ruidoso, el más mediático a propósito de la muerte del marxismo como fin de la historia.

\section{II.- Postmarxismo y Deconstrucción}

¿Qué se canceló en el marxismo? ¿Qué queda de él? Resulta interesante notar que, a pesar de cierta crisis teórica y del fracaso político, un buen número de teóricos, inspirados en Marx, están realizando aportes fundamentales para la comprensión de la sociedad

3 Lyotard, Jean-Francois, La condición postmoderna, Cátedra. Madrid. 1986

4 Marx, C, El Capital. Crítica de la economía política (1867-2017)

5 Derrida, Jacques. Espectros de Marx. El trabajo de la deuda, el trabajo del duelo y la Nueva Internacional. Madrid, Ed. Trotta, 1998

$6 \quad$ Fukuyama, El fin de la historia y el último hombre, Editorial Planeta, Barcelona 1992. 
actual. Se trata, no de voces "marginales", sino por el contrario de autores fundamentales, establecidos en lugares muy influyentes en la academia mundial, que con sus libros han establecido los debates más interesantes en el campo del pensamiento social contemporáneo.

Por Postmarxismo se entiende a aquellas posiciones que, luego de la influencia de la deconstrucción y el post-estructuralismo, siguen explorando las lógicas de la acumulación del capital, la fertilidad del conflicto, y la necesidad de construir categorías más abarcadoras que tomen en cuenta lo económico, lo político y lo simbólico como factores constituyentes del todo social. Se trata, sobre todo, de posiciones teóricas que, aunque afirman la importancia del universalismo, niegan la posibilidad de cierres absolutos e intentos de totalización autoritarios. En estos nuevos marxismos no hay un agente específico que garantice, por sí mismo, la posibilidad de un cambio histórico. Se postula, por el contrario, el carácter siempre incompleto de las identidades sociales, la importancia del lenguaje y la definición de realidad es una construcción social que se funda en relaciones de poder que siempre implican desigualdad y conflicto. Algunos ejemplos: Derrida, Jacques. "Inyucciones de Marx" En: Espectros de Marx. El estado de la deuda, el trabajo del duelo, la nueva internacional. Madrid: Trotta, 1995. Pensemos en los Espectros de Marx de Derrida y el irrealizado Grandeur? de Marx de Deleuze, sólo como otros testigos contemporáneos.

Los espectros de Marx. ¿Por qué este plural? ¿Es que hay más de uno? Más de uno puede significar multitud, cuando no masas, la horda o la sociedad, o también alguna población de fantasmas con o sin pueblo, alguna comunidad con o sin jefe -pero también el menos de uno de la dispersión pura y simple-. Sin agrupación posible. Además, si el espectro está siempre animado por un espíritu, cabe preguntarse quién se atrevería a hablar de un espíritu de Marx, más seriamente aún: de un espíritu del marxismo. 8

Espectros es una propuesta de lectura de los textos de Marx, que previene de la seducción del lenguaje que conlleva todo discurso, todo logos. gracias a que de una manera reiterada nos indica sus márgenes. En este tenor, es de subrayarse la crítica demasiado exacerbada que hace Marx a uno de los hegelianos de izquierda que se alinea junto a

$7 \quad$ "Fundamentos de la crítica de la economía política" (Grudrisse der kritik der politischen okonomie (rohentwurf)), mejor conocidos como Grundrisse, esbozo de 1857-1859, escrito por Marx durante su exilio en Londres

8 Derrida, Jacques. Espectros de Marx. El trabajo de la deuda, el trabajo del duelo y la Nueva Internacional. Madrid, Ed. Trotta, Capítulo 1. Derrida dio una conferencia en la Universidad de California (Riverside) los días 22 y 23 de abril de 1993, como apertura del coloquio "Whither marxism?" (traducible como ¿̇Adónde va el marxismo?). El texto apareció en francés en 1993, en inglés, en una versión abreviada en New Left Review, no 205, may-jun de 1994 y en castellano (traducción directa del francés) en septiembre de 1995 bajo el título Espectros de Marx. El estado de la deuda, el trabajo del duelo y la nueva internacional, Trotta, Madrid, 1995. 
Feverbach, Max Stirner, y que Derrida hace notar con agudeza. Al denunciar Marx a este hegeliano que pretende retrotraerse a un "único", a un yo singular que intenta sustraerse de toda espectralidad abstracta y universal, que sin embargo teme a su propio y siniestro fantasma, tal vez el mismo Marx, quede atrapado en su caza de fantasmas, invocando a otros. Pero ello no quita el valor emancipador, desalienante que podemos hallar en los textos marxistas. Algo parecido, en otra obra, opera Derrida con respecto a Freud y a Lacan?, Ios cuales al tratar de burlar a los fantasmas, mediante el Stoff del sueño o de la letra, no dejan de incurrir en cierto semanticismo u ontologismo.

Hay, hoy en día, en el mundo, un discurso dominante, o más bien en trance de hacerse dominante, respecto a la obra y al pensamiento de Marx, respecto al marxismo, respecto a todos los rostros pasados de la Internacional socialista y de la revolución universal, respecto a la destrucción más o menos lenta del modelo revolucionario de inspiración marxista, respecto al derrumbamiento rápido, precipitado, reciente, de las sociedades que han intentado ponerlo en marcha, al menos en lo que llamaremos de momento, citando otra vez el Manifiesto, la "vieja Europa", etc. Este discurso dominador tiene, con frecuencia, la forma maníaca y jubilosa que Freud asignaba a la fase llamada triunfante en el trabajo del duelo. La incantación se repite y se ritualiza, mantiene y se mantiene con fórmulas, como prescribe toda magia animista. Vuelve a la cantinela y al refrán. Al ritmo de un paso cadencioso, clama: Marx ha muerto, el comunismo está muerto, bien muerto, con sus esperanzas, su discurso, sus teorías y sus prácticas, jviva el capitalismo, viva el mercado, sobreviva el liberalismo económico y político!"10

\section{III.- Políticas de la memoria, un fantasma recorre Europa}

Es así como Derrida pone en actualidad a Marx en nombre de una "política de la memoria". Derrida probablemente pensó en un título como, Espectros de Marx, porque el mismo remite a todas las formas de un asedio. En el momento en que un nuevo desorden mundial intenta instalar su neocapitalismo y su neoliberalismo, ninguna denegación consigue liberarse de todos los fantasmas de Marx. La hegemonía sigue organizando la represión y, por tanto, la confirmación de un asedio. El asedio pertenece a la estructura de toda hegemonía.

Aquí se trata de cartografiar las derivas epistémicas, los devenires geopolítico y las hibridaciones fronterizas de El capital, su excéntrica dimensión performativa en tanto que acontecimiento, como su

9 Derrida, Jacques. La tarjeta postal. De Sócrates a Freud y más allá. Editorial: Siglo XXI-México, 2001

10 Derrida, Jacques. Espectros de Marx. El trabajo de la deuda, el trabajo del duelo y la Nueva Internacional. Madrid, Ed. Trotta, 1998. pp. 63-89 
capacidad de ser repetible de manera discontinua en contextos diferentes al europeo centro-occidental.

Si bien no todo símbolo determinante de lo cotidiano requiere de una explicación filosófica, situar a un grupo de estudio filosófico bajo una identidad, implica una sustentación rigurosa y filosófica. De tal suerte, "espectros" remite a una tradición literaria que se haya enraizada principalmente en la obra de Shakespeare, Hamlet. Aquí, podríamos indicar que el nombre se sustenta en la reflexión que deviene de la relación entre el Manifiesto Comunista y el pasaje de Hamlet sobre la aparición de un espectro -en Marx el comunismo y en Hamlet el padre-, donde el asedio del espectro es pavorosamente determinante en las dos obras, o más precisamente, la angustia por la aparición, por la llegada, los cuándos, los ahora, ¿los ya? Así, la emblemática entrada del manifiesto donde se enuncia: "Un espectro asedia a Europa, el espectro del comunismo" implica una dramatizada tremenda sobre el arribo del fantasma del comunismo, y bueno la pregunta metafísica que sigue ¿Llegará? En ese tenor, Derrida abre la necesidad de volver a pensar en la reaparición del asedio, y aquí nuevamente, los cuándos, los ahora ¿los ya? Con todo esto, hoy, aparece nuevamente el enunciado: "Un espectro (...)" Es el espectro de un fantasma aparentemente pasado, que alguna vez fue presente en El Manifiesto Comunista de Marx, "Un espectro asedia Europa: el espectro del comunismo", así, de esta manera, empiezan las indagaciones ontoretóricas de Derrida en este libro: toda la historia (cultural) humana es una historia de fantasmas, de entes espectrales que aparecen y reaparecen más allá del presente viviente mismo.

No resulta raro que una gran filosofía avance $y$, al mismo tiempo, retroceda, circunscribiendo ininterrumpidamente un núcleo central de pensamiento y una intuición metódica fuerte y coherente. En sus Espectros de Marx, Derrida da demostración del avance de su filosofía, restituyendo el método a los orígenes de la deconstrucción, al ovillo histórico específico que condicionó su génesis: "Semejante deconstrucción hubiera sido impensable e imposible en un espacio premarxista. La deconstrucción sólo ha tenido sentido e interés como una radicalización, es decir, también en la tradición de cierto marxismo, con cierto espíritu del marxismo". 11

En efecto, parece bastante claro que la deconstrucción nace y se desarrolla en el clima teórico de la Rue d'Ulm, al cual nutre a su vez, lugar donde, sucesiva pero no menos contemporáneamente, se desarrolla el trabajo de Althusser, Foucault y Derrida. En particular, cabe atribuir a la méthode symptomal y a la interpretación estructural de la intromisión de los "aparatos ideológicos de Estado", entre Lire le Capital y el texto Sur la reproduction -dentro de un intercambio recíproco-, la génesis de la deconstrucción.

11 Jacques Derrida, Espectros de Marx, p. 106 
Pero la reivindicación deconstruccionista de una tradición y un espíritu marxistas resulta mucho más pertinente si, más allá de la mera genealogía, consideramos la dirección rigurosamente crítica que encarna la deconstrucción -una dirección hermenéutica (ontológica a su manera) que participa de las dinámicas del mundo histórico y conceptual del capitalismo, pero para oponerse a éstas originariamente como desmitificación: de su lenguaje, en primer lugar, y, por ende, a través y tras el lenguaje, de las "metafísicas de lo propio" y del "logocentrismo" estatal encapsulados en el capitalismo. Así pues, los Espectros de Marx son, de algún modo, los espectros del capital. Los que aparecen en Das Kapital, pero sobre todo los que hoy configuran una sociedad unánimemente definida "capitalista" por la economía política y por la opinión pública.

Trasladado al terreno de la crítica de la economía política, este proyecto de lectura espectral de-la ideología se aplica a las categorías de la sociedad del capital y se desarrolla ontológicamente hasta afianzarse definitivamente en Das Kapital (de ello habla Derrida en las páginas 180-192). Los fantasmas allí referidos tienen una singular pertinencia ontológica: revelan, en efecto, el pleno funcionamiento de la ley del valor. Fantasma es el movimiento de un abstracto que se materializa y se torna potente: ante todo el valor, que, con movimiento exangüe, vampiriza el trabajo obrero y, de tal suerte, transmutándose en plusvalor, se torna capital; el dinero, en segundo lugar, que con movimiento circular se verticaliza y se consolida como moneda, como capital financiero y como potencia parasitaria; la tecnología, por último, pero también en principio, que, acumulándose, construyendo líneas integradas y fijas de mando objetivado, disciplina y jerarquiza la sociedad y la vida. De este modo, la fenomenología de la producción capitalista descrita por Marx en Das Kapital muestra cómo, a través de este movimiento fantasmático, se constituyen una genuina metafísica del capital así como la autonomía de su poder. Pero en la medida misma en que se desarrolla con formas fantasmáticas y se autonomiza del capital, esta fenomenología -sostiene Marx- enmascara la génesis real del proceso de desarrollo del capital. Para disipar la autonomía ficticia del capital y las categorías que la interpretan, aśi como para desmistificar el orden necesario de la economía política del mercado, es preciso remitirse de nuevo, a juicio de Marx, al modo de producción e intercambio, analizar la poderosa falsificación de la centralidad del trabajo obrero que allí se opera, rompiendo, por consiguiente, el funcionamiento de la ley del valor y reconstruyendo, sobre una base liberada, las dinámicas productivas de la sociedad y de la vida. ${ }^{12} \mathrm{~A}$ este respecto, hay que señalar una primera y sustancial aportación de la deconstrucción a la puesta al día del proyecto de crítica del capitalismo.

12 Jacques Derrida, Espectros de Marx. El estado de la deuda, el trabajo del duelo y la nueva Intenacional, Madrid, 1995 


\section{IV.- Jacques Derrida: Espectros de Marx; El Estado de la deuda, el trabajo del duelo y la nueva internacional}

-A propósito de una conferencia sobre el "Derrumbe del Marxismo" en la Universidad de California durante la primavera de 1993, el filósofo de la Descontruccion fue invitado a presentar su discurso sobre el tema. El resultado: un libro de casi trescientas páginas titulado Espectros de Marx: El Estado de la deuda, el trabajo del duelo y la nueva internacional. Aquí Derrida, quiere descontruir la figura a través del fantasma. Que puede significar los cambios de la labor y producción en la nueva era de la Globalización y las Deudas Externas? Que legado, o sea que nos dicen los fantasmas del comunismo? ¿े Que nos propone la nueva orden social/mundial después de la caída del Muro de Berlín de 1989? Central para esta crítica de doble gesto (Marx y lo fantasmagórico, el fantasma siempre "regresa") es la idea de rescatar a Marx como institución de la Justicia y la Responsabilidad. El espectro dice Derrida es "un política de la memoria". Un fantasma recorre Europa...termina/empieza diciendo Marx en el Manifiesto. En efecto, Marx, como Freud, sabía de la eficacia de los fantasmas, de los espíritus. La mercancía se convierte en fantasma en el momento que el que la produce ya no se encuentra reflejado en ella, en el momento en que le resulta extraña, ajena y él, el productor, se enajena. El cine es el recinto por naturaleza de lo fantasmagórico, pero hay algo más. Esa ciencia de los fantasmas describe en relieve la condición del capitalismo. Más allá de la producción en masa, el capitalismo se ha preocupado por la conquista de la libido del sujeto.

Espectros fue el primer título que Marx pensó para su Manifiesto. Derrida lo recupera en este libro para realizar una crítica de la herencia de Marx en el mundo contemporáneo, una crítica vertida desde su particular teoría filosófica: la deconstrucción.

Jacques Derrida critica un nuevo dogmatismo, una nueva intolerancia que se ha adveñado de Europa, el dogmatismo capitalista que insiste en la muerte de Marx y del marxismo. Para Derrida es necesario conjurar de nuevo los espectros, los "espíritus" marxianos que perviven en la cultura europea, no para rehabilitar aquello en que estamos de acuerdo que no es necesario repetir, sino para romper la censura y la prohibición que estigmatizan todo lo relacionado con él, manteniendo vivo el diálogo con los que se declaran partidarios suyos.

Partiendo de la distinción entre la justicia y el derecho, y debatiéndose entre dos puntos de vista (el de la herencia y el del mesianismo del filósofo alemán), Espectros de Marx es sobre todo el testimonio ? o la apuesta intempestiva? de una toma de posición. Derrida se muestra partidario de un cierto marxismo que contrarreste la imperante doctrina capitalista y que acalle las constantes e insistentes voces que, en un determinado espacio geopolítico, niegan la pervivencia del pensamiento de Marx y afirman su imposible recuperación. 
Espectros de Marx no es exactamente un libro sobre Marx; es una lectura de Marx en el contexto de la derrota de quienes se proclamaron y fueron aceptados como sus herederos, junto con el triunfo geopolítico de su enemigo, el liberalismo económico y político.

Ante la caída de la Unión Soviética, una de las encarnaciones del espectro comunista, y el triunfo proclamado, por Fukuyama, del pensamiento neoliberal, con su democracia y libre mercado, Derrida nos obliga a reconocer la actualidad de la lectura del texto de Marx. Pues, cabe reiterar que, Espectros de Marx no es un libro sobre Marx, sino es una lectura de Marx. Lectura que nos hace descubrir a un Marx más allá del estereotipo que inevitablemente se fue sedimentando entre quienes lo exaltaron y lo repudiaron, pero que probablemente nunca lo leyeron.

Las mutaciones del capitalismo contemporáneo como sistema han venido produciendo una serie de modificaciones en el plano cultural, en los órdenes teóricos, artísticos y literarios. Es este un fenómeno que acompaña al capitalismo desde su originariedad constitutiva en Europa, que de local y medieval (mística, religiosa) se transforma indefectiblemente en moderna o industrial-tecnológica universal.

Figuras deconstruidas por Marx como espectros (Gespensten), alucinaciones, productos de la ceguera del idealismo, del anarquismo, del socialismo utópico y de la economía política, que insistían en localizar el origen allí donde no se diseñaba más que un efecto.

Resultado de ese "salto tecnológico", a la altura del siglo XIX la cultura pasa de un estado afirmativo (el Renacimiento, la Edad Media poscartesiana, la llustración) a un estado negativo o desencantado en el que los problemáticos muerte, fin y anti (de la filosofía, del arte) exponen lo que Nietzsche sintetiza con el término nihilismo, una de las figuras de la decadencia.

Esta tensa colisión entre economía y cultura acrecentada a lo largo del siglo XX y cuyo rasgo fundamental es el negativismo desacralizador de valores que pretendieron ser absolutos.

\section{V.- Marx, Derrida, El gesto Político}

En Los espectros de Marx ... Derrida pone en escena lo que con singularidad llama el "gesto político" del pensar. En el interior de este y protegiendo una crítica de inspiración marxista, la figura de Marx y sus textos capitales (El manifiesto comunista, La ideología alemana y El capital) vienen a ser el eje central de la sobre-lectura derridiana 0 aventuras de la diferencia.

¿Qué es aquello que deja ver(se) al gesto político en esa aparente despolitización de las cosas? Los espectros de Marx, el nombre común y 
el nombre propio estaban anunciados de allí que se haya tornado una costumbre cool releer el Manifiesto del Partido Comunista. Se sabía que un fantasma recorre a Europa, el fantasma del comunismo.

"De esta manera empiezan las tribulaciones onto-retóricas de Derrida en este libro: toda la historia (cultural) humana es una historia de fantasmas, de entes espectrales que aparecen y reaparecen más allá del presente viviente mismo. Lo que se hace ver con fuerza para pensar la actual capitalización es el "estar" de un fantasma o el regreso "eficaz" de un espíritu."13

Esa presencia no-presente, ese "estar-ahí" de un ausente que corresponde a una esencia que "nos mira" y "nos sentimos mirados por él" es Marx (el espíritu de Marx ) o el juicio total innegable sobre la capitalización. Razón tenía Nicanor Parra cuando decía "Despacito por las piedras. El cadáver de Marx aún respira".

Postmarxismo comprende aquellas posiciones que, luego de la influencia de la deconstrucción y el post-estructuralismo, siguen explorando las lógicas de la acumulación del capital, la fertilidad del conflicto, y la necesidad de construir categorías más abarcadoras que tomen en cuenta lo económico, lo político y lo simbólico como factores constituyentes del todo social. Se trata, sobre todo, de posiciones teóricas que, aunque afirman la importancia del universalismo, niegan la posibilidad de cierres absolutos e intentos de totalización autoritarios. En estos nuevos marxismos no hay un agente específico que garantice, por sí mismo, la posibilidad de un cambio histórico. Se postula, por el contrario, el carácter siempre incompleto de las identidades sociales, la importancia del lenguaje y la definición de realidad es una construcción social que se funda en relaciones de poder que siempre implican desigualdad y conflicto.

- Ahora bien el fracaso del comunismo real, acontecimiento que algunos han llamado "la muerte de Marx", aludiendo a una derrota del marxismo efectuada no sólo en la praxis, sino también en el plano teórico e intelectual. La complejidad de esta empresa -entender los Espectros de Marx, de Derrida, (El Estado de la deuda, el trabajo del duelo y la nueva internacional) no es exactamente un libro sobre Marx; es una lectura de Marx en el contexto de la derrota de quienes se proclamaron y fueron aceptados como sus herederos, junto con el triunfo geopolítico de su enemigo, el liberalismo económico y político. Fracaso como praxis: ni la revolución realizó el socialismo ni el capitalismo fue destruido como efecto de ciertas leyes deterministas o de la acción consciente del sujeto revolucionario. Y fracaso como teoría: el marxismo aseguraba ser la ciencia social de la modernidad, alardeando de conocimientos sólidos en materia de economía, historia, sociología, política y filosofía. Todo este cúmulo de 'saberes científicos'

13 Ravelo Cabrera, Paul, "Marx, Derrida, el gesto político y la supercapitalización mundial", Revista de filosofía (San José), Costa Rica, Clase, Vol 40, N. ${ }^{\circ} 102$, pp. 77-85 
ha sido incapaz de explicar no ya la dinámica evolutiva capitalista, sino, lo que es definitivamente invalidante, su propia crisis y desintegración.

- Para entender por qué nos cuesta tanto pensar hoy la revolución debemos atender a dos acontecimientos clave que ya se han venido apuntando: 1. el primero respecto al clima intelectual y político que vive europa tras la liquidación del proyecto de la Modernidad; el segundo: el fracaso del comunismo real, acontecimiento que algunos han llamado "la muerte de Marx", aludiendo a una derrota del marxismo efectuada no sólo en la praxis, sino también en el plano teórico e intelectual 2. La complejidad de esta empresa -entender la (im)posibilidad revolucionaria- también se debe al "espesor" del propio concepto, bajo el que subyacen ideas cuyo recorrido conforma la historia misma del pensamiento occidental moderno (y buena parte de sus desencantos).

Quizá ya no se tenga miedo a los marxistas, pero se teme aún a ciertos no marxistas que no han renunciado a la herencia de Marx, criptomarxistas, seudo o para "marxistas", que estarían dispuestos a tomar el relevo, bajo unos rasgos o entre unas comillas que los angustiados expertos del anticomunismo no están preparados para desenmascarar.

En la obra maestra de Marx, Capital, Vol. I, publicada por primera vez una década después de que escribiese los Grundrisse, el poder abstracto e impersonal del capital era en sí mismo un actor histórico, un sujeto que se desarrollaba solo. El tratamiento extendido de Marx sobre los orígenes históricos del capitalismo se colocó al final del libro, bajo la categoría "Acumulación Primitiva del Capital", después de que el lector haya sido conducido a través de un estudio conceptual y empírico sobre el mismo capital moderno.

- Finalmente la investigación, se plantea el problema de los posibles vínculos entre la primera fase de la obra de Marx y la estética del idealismo alemán, particularmente el lazo entre la concepción marxiana de una revolución estética más profunda que la revolución política y la idea en Schiller de una "revolución de la sensibilidad". Se trata, finalmente, de indagar sobre las relaciones de continuidad y de discontinuidad que hay entre aquel conjunto de categorías en la obra marxiana temprana y la emergencia de los conceptos de "fuerza de producción" y de "división del trabajo", con el objetivo de esclarecer la problemática de la obra de arte en el marco general de una crítica de la economía política.

Ahora bien, como desencadenamiento de las escatologías mesiánicas, el marxismo sigue siendo todavía necesario pero con tal de que se le transforme y adapte a nuevas condiciones y a otro pensamiento de lo ideológico, con tal de que se le obligue a analizar la nueva articulación de las causalidades tecno-económicas y de los fantasmas religiosos, la dependencia de lo jurídico al servicio de poderes socio-económicos o 
de Estados que, a su vez, no son nunca totalmente independientes con respecto al capital (pero ya no hay, no ha habido jamás, capital ni capitalismo en singular, solamente capitalismos - de Estado o privados, reales o simbólicos, siempre ligados a fuerzas espectrales-, capitalizaciones más bien, cuyos antagonismos son irreductibles.) ${ }^{14}$

Para Derrida "no hay futuro sin Marx" por eso recibe a su fantasma con alegría. Como consuelo, podemos evocar "un cierto espíritu de Marx". ¿Y cuál es ese cierto "espíritu"? El de una "cierta" vocación mesiánica sin mesianismo. El paroxismo tecnológico, el creciente poder de los mass media sobre la producción, el universalismo del consumo, la desconfianza en la idea de una humanidad compartida, el proceso de plus valor, es decir, la Verdad misma de todo aquello que acompaña al capital desde su salida de las ruinas de la sociedad feudal.

\section{VI.- Noticias de la Antigüedad Ideológica - Marx/Esenstein/El Capital}

En el mundo, hay hoy un discurso dominante, una nueva dogmática respecto a la obra y al pensamiento de Marx, respecto al marxismo (que es, quizás, otra cosa), respecto a todos los rostros pasados de la Internacional socialista este discurso tiene, con frecuencia, la forma maníaca, jubilosa e incantatoria que Freud asignaba a la fase llamada triunfante en el trabajo del duelo. La incantación se repite y se ritualiza, mantiene y se mantiene con fórmulas, como prescribe toda magia animista. De allí que Marx haya muerto, con sus esperanzas escatológicas, su discurso, sus teoría y su praxis! 15

Por último, está la cultura erudita o académica, especialmente la de los historiadores, los sociólogos y los politólogos, la de los teóricos de la literatura, los antropólogos, los filósofos, en particular los filósofos políticos, cuyo discurso es a su vez sustituido por la edición académica, comercial y también mediática en general. Pues no escapará a nadie que los tres lugares, formas y poderes de la cultura que acabamos de identificar (el discurso expresamente político de la "clase política", el discurso mediático y el discurso intelectual, erudito o académico) están más que nunca soldados por los mismos aparatos 0 por aparatos indisociables. Estos aparatos son, sin duda, complejos, diferenciales, conflictivos, sobredeterminados. Pero sean cuales sean los conflictos entre ellos, sean cuales sean sus desigualdades 0 sus sobredeterminaciones, (se) comunican y concurren en todo momento hacia el punto de mayor fuerza para garantizar la hegemonía o el imperialismo en cuestión. Lo hacen gracias a la mediación de lo que se

14 DERRIDA, Jacques. Espectros de Marx. El trabajo de la deuda, el trabajo del duelo y la Nueva Internacional. Madrid, Ed. Trotta, 1998. pp. 63-89

15 DERRIDA, Jacques. Espectros de Marx. El trabajo de la deuda, el trabajo del duelo y la Nueva Internacional. Madrid, Ed. Trotta, 1998. pp. 63-89 
llama, precisamente, los media en el sentido más amplio, más móvil y, teniendo en cuenta la aceleración de los adelantos técnicos, en el sentido más invasor de este término. La hegemonía político-económica, al igual que la dominación intelectual o discursiva, pasa, como jamás lo había hecho en el pasado, ni en tal grado ni bajo tales formas, por el poder tecno-mediático -es decir, por un poder que a la vez, de manera diferenciada y contradictoria, condiciona y pone en peligro toda democracia.

Ahora bien, uno de los más respetados y lúcidos cineastas alemanes, Alexander Kluge ${ }^{16}$, ha hecho realidad el proyecto del realizador soviético Serguei Eisenstein: la filmación de El Capital, de Karl Marx, en "Noticias de ta Antigüedad Ideológica - Marx/Esenstein/El Capital"17 un desmesurado film de Alexander Kluge, de 2008, de más de 9 horas de duración y que gira en torno del proyecto irrealizado de Eisenstein. Filmar El Capital, pero no como un documental, no como películas de divulgación, para proyectar en las escuelas y las fábricas de la extinta Unión Soviética, sino como un relato construido con técnicas de flujo de conciencia tomadas de "Ulises", de James Joyce, cuestión que, sin embargo, se convierte en un discurso polifónico.

Este homenaje se ha convertido en una monumental y osada composición de secuencias fílmicas, documentales y de ficción; un filmensayo de casi diez horas.

Un ensayo cinematográfico que habla de Marx en el lenguaje de Hölderlin, una banda sonora donde se deleita con incursiones en la música contemporánea y óperas de Wagner y donde va entrevistando a importantes pensadores de Alemania, como a Hans Magnus Enzensberger sobre el Viernes Negro de 1929 o a Peter Sloterdijk sobre las metamorfosis de la plusvalía. Kluge ha releído El Capital y ha buscado las imágenes que hoy podrían traducirlo.

¿Qué es lo que se proponía filmar Eisenstein? Los apuntes de Eisenstein para "cineficar" El capital, de Karl Marx. ¿Cómo se leen y escuchan hoy los textos que Marx escribió hace casi 140 años?: una aproximación 'de oído'. ¿Qué distingue la Modernidad de la Antigüedad cuando se trata de ideología? El dinero, ¿̇cómo se explicaría a sí mismo si pudiera hablar? ¿̇El capital puede decir "yo"? Dietmar Dath sobre cuáles son los ejes del gran libro de Marx. Sophie Rois sobre el dinero, el amor y Medea. Para terminar: La reencarnación de Tristán en la piel de los marineros condenados a muerte del Acorazado Potemkin (por Werner Schroeter).

Alan Pauls resume bien lo que se dice en la película de Kluge sobre las características de esa obra que nunca se filmó:

16 Alexander Kluge, Nachrichten aus der ideologischen Antike-Marx/Eisenstein/Das Kapital (Noticias de la antigüedad ideológica Marx/Eisenstein/El Capital) Alexander Kluge, Alemania. VOSE 570' (9h 30') DigiBeta, 2008.

17 "Nachrichten aus der ideologischen Antike - Marx/Eisenstein/Das Kapital" 
"...filmar El capital como si fuera el Ulises. Una historia que transcurre en un solo día, el monólogo interior de la mujer de un obrero, un film que proceda no por sucesión ni por causalidad sino por encadenamiento de asociaciones libres."

Se diría que al darle semejante duración a su película, Kluge quiso dotarla de una excepcionalidad equiparable al proyecto de Eisenstein. O soñó, o tuvo noticias de que Eisenstein planeaba que su película fuera interminable y adoptó la idea para la suya. Pero "Noticias de la Antigüedad Ideológica" es otra cosa, por supuesto. Kluge, en rigor, no realiza el proyecto de Eisenstein, del que no existe ni siquiera un boceto de guión. A lo sumo "Noticias..." es "El Capital de Karl Marx", según Alexander Kluge. Sin monólogo interior, sin encadenamiento de asociaciones libres, sin unidad de tiempo, y con muchas entrevistas a intelectuales y artistas, gran cantidad de carteles, cada uno con su tipografía única, toques de humor (se me ocurre alemán), y hermosos videoclips de uno o dos minutos de duración.

Muchos intelectuales importantes han apoyado -por así decirlo, a título póstumo- el marxismo: pensemos en Spectres de Marx de Derrida y el irrealizado Grandeur de Marx de Deleuze, junto con otros testigos contemporáneos de la crisis mundial ("ahora todos somos socialistas", etc.). ¿Es la nueva película de Kluge una de esas confirmaciones? ¿Sigue siendo marxista? ¿Lo ha sido alguna vez? ¿Y qué significaría hoy "ser marxista"? El lector anglo-estadounidense bien puede preguntarse cómo se relacionan los alemanes en general con su gran clásico nacional, cuando se rumorea la aparición de cientos de grupos de lectura de El capital bajo los auspicios del ala estudiantil del Linkspartei. Kluge lo dice en el material impreso adjunto: La posibilidad de que se produzca una revolución europea parece haberse desvanecido; y junto con ella la creencia en un proceso histórico que la conciencia humana puede modelar directamente. Ese Kluge cree en la pedagogía colectiva, sin embargo, y en la reapropiación de los procesos de aprendizaje negativos por los positivos, en lo que podríamos denominar una reorientación de la experiencia mediante una reconstrucción de "sentimientos" (un término clave o técnico para él): esto no sólo se evidencia en los comentarios interpretativos sobre sus diversos relatos y películas, sino también en enormes volúmenes teóricos como Geschichte und Eigensinn (Historia y obstinación), escrito en colaboración con Oskar Negt. ${ }^{18}$

Se intercalan muchos fragmentos y fotogramas de películas, la mayoría del cine mudo, y dramáticas imágenes gráficas de textos marxianos y eisensteinianos dejan claro que los intertítulos del cine mudo podían ser de hecho electrizantes, si se resucitan en un color audaz y una tipografía espectacular. Es la propia versión de Kluge sobre el "montaje de

18 Jameson, F. (2009). Marx y el montaje, Sobre Noticias de la antigüedad ideológica de Alexander Kluge, la Fuga, Revista de Cine. 
atracciones" eisensteiniano (este cineasta podría decir "de sentimientos"). A los espectadores no acostumbrados a estas prácticas bien puede parecerles un increíble revoltijo. Pero también ellos pueden aprender finalmente a navegar por este prodigioso espacio arqueológico: sin llegar a ser un museo pleno y profesionalmente organizado, ésta es una inmensa excavación, en la que todo tipo de personas, aficionados y especialistas por igual, se mueven en diversos estados de actividad, algunos arreglándose las cejas o comiéndose un emparedado, otros tumbados en el suelo para limpiar el polvo de una mandíbula, y otros más clasificando objetos varios en las cajas adecuadas sobre mesas protegidas por una tienda, cuando no echando una siesta o enseñando a un novato, recorriendo una estrecha senda para no pisar los vestigios. Es nuestro primer contacto con la antigüedad ideológica.

Ahora ¿A qué llamamos fetichismo de la mercancía? El poder delicado y a la vez arremetedor del capital, ¿qué hechizos produce? ¿Por qué los hombres no son dueños y señores de su producción? ¿ Qué significa "asociación de productores libres"? ¿Por qué fracasan las revoluciones? ¿Por falta de tiempo o por principio? ¿Qué significa que todas las cosas son personas encantadas? Con una película de Tom Tykwer sobre la enorme riqueza de detalles que aparece en una imagen cinematográfica a medida que uno se interesa por el proceso de producción de las cosas.

\section{VII.- Los Grundrisse, Karl Marx}

"Fundamentos de la crítica de la economía política" (Grudrisse der kritik der politischen okonomie (rohentwurf)), mejor conocidos como Grundrisse19, esbozo de 1857-1859, escrito por Marx durante su exilio en Londres, en uno de los momentos más difíciles de su vida, al tiempo que arreciaba la primera gran crisis financiera que comenzó a finales de 1857 y que se convirtió en la primera crisis económica a nivel mundial, causada por el declive de la economía internacional y la sobreexpansión de la economía doméstica.

En Grundisse, Marx esboza la ley de la tendencia decreciente de la tasa de ganancias como un factor clave para explicar este tipo de crisis financieras, que desarrolla también en: "Crítica de la Economía Política", "El Capital" y "Teorías de la plusvalía"; la cual considera que el valor de los medios de producción (maquinaria, oficinas y otros equipos), con el tiempo, aumenta en relación con el valor de la fuerza de trabajo (el coste de emplear una fuerza de trabajo determinada). Marx denominó a esto, como: "la composición orgánica creciente del capital". Como el

19 Marx, K. (1971). Elementos fundamentales para la crítica de la economía política. (Borrador) 1857-1858. Tomo I. Madrid: Siglo XXI. pp, 20-30. 
valor, las ganancias, sólo son creadas por el poder de la fuerza de trabajo. El valor es producido por la fuerza de trabajo, con el tiempo, y disminuye en relación con el coste de la inversión en medios de producción y fuerza de trabajo. La tasa de ganancias tiende a caer. Lo cual se basa en dos supuestos: 1) la ley del valor de uso/cambio y de los plusvalores, explica cómo estos son creados por el trabajo vivo y, 2) la acumulación capitalista conduce a un aumento de la composición orgánica del capital. Desde las herramientas manuales a las fábricas, la maquinaria, a grandes buques cargueros, hay un enorme aumento de la productividad del trabajo en el capitalismo como consecuencia de la mecanización. Lo cual crea nuevos puestos de trabajo para el trabajo vivo, pero que es esencialmente un proceso de ahorro del trabajo vivo en términos relativos. Mientras que cada unidad de un nuevo medio de producción puede contener menos valor (debido al menor precio de la producción de esa tecnología) que una unidad de un medio de producción más antiguo, por lo general el viejo es sustituido por medios de producción nuevos y diferentes, o por un nuevo sistema de medios de producción que contiene más valor total que el valor de los medios de producción que ha sustituido.

Sobre esta ley, Marx expresará en una carta a Engels en fecha tan tardía como 1868, más de diez años después del su primer desarrollo: "fue uno de los mayores triunfos sobre el puente de asnos de todos los economistas anteriores".

La ley en términos generales, explica que el objetivo de la inversión capitalista no es una mayor productividad; es un mayor beneficio, por lo que la productividad, y el trabajo vital involucrado, son un mal necesario, que si fuera posible, será prescindido cada vez más. No obstante, mientras esto no sea posible, para aumentar las ganancias, el capital necesita una mayor productividad y nuevos medios de producción que ahorren trabajo. La ley sobre la tendencia decreciente de la tasa de ganancias de Marx permite hacer una predicción aún más importante: que el modo de producción capitalista no será eferno, que es transitorio en la historia de la organización social humana. La ley de la tendencia predice que, con el tiempo, habrá una caída en la tasa de ganancia a nivel mundial, provocando crisis cada vez más cruentas y con un carácter devastador. Hay trabajos de análisis marxista modernos que confirman que la tasa mundial de ganancias ha caído en los últimos 150 años

La evidencia empírica de la relación causal entre ganancia e inversión, ha sido ampliamente referida en distintas tradiciones de economía política marxista, en torno a las distintas crisis del siglo XX. En el período previo a la Gran Recesión 2008-9, es posible relacionar casualmente la inversión y el PIB real en EE.UU, y dar cuenta cómo la masa de ganancias corporativas alcanza su techo a mediados de 2006, la inversión y el PIB dos años más tarde. Las ganancias vuelven a recuperarse a finales de 2008 y la inversión un año más tarde. Hay dos 
regularidades básicas de acuerdo con lo datado: que un cambio en las ganancias tiende a ser seguido un año después por un cambio en la inversión en la misma dirección; y que un cambio en la inversión es generalmente seguida en pocos años por cambios en los beneficios en la dirección opuesta. Así pues, existe un ciclo. A partir de estos resultados, de la "regularidad" del ciclo económico, y del hecho de que la rentabilidad se estancó en 2013 y disminuyó en 2014 (y la masa de ganancias en luego del 2015) después de crecer entre 2008 y 2012, se puede concluir con cierta seguridad que una recesión de la economía estadounidense, que será también parte de una crisis económica mundial como la Gran Recesión, volverá a ocurrir en los próximos años. En breve, lo que la ley sobre la tendencia decreciente de la tasa de ganancias de Marx, permite hacer una predicción aún más importante: que el modo de producción capitalista no es un hecho natural perse, es un producto de condiciones históricas, y por ende. como la historia de la organización social humana lo ha mostrado, es transitorio. El capitalismo no siempre ha existido y tiene límites en última instancia, en concreto, el propio capital es su propio pecado original que le ha fijado endógenamente su "fecha de caducidad". Esa es la esencia de la ley de la rentabilidad de Marx sobre el sistema capitalista, qué él mismo bautizó, explicó y predijo la naturaleza de su final.

"Lo que se abarata es la máquina individual y sus partes componentes, pero también se desarrolla un sistema de maquinaria; la herramienta no es simplemente reemplazada por una sola máquina, sino por todo un sistema ... A pesar del abaratamiento de los elementos individuales, el precio de todo el conjunto agregado aumenta enormemente" (K. H. Marx, Grundisse). 


\section{Bibliografía}

- Lyotard, Jean-Francois, La condición postmoderna, Cátedra. Madrid. 1986

- Marx, C, El Capital. Crítica de la economía política (1867-2017)

- Fukuyama, El fin de la historia y el último hombre, Editorial Planeta, Barcelona 1992.

- Marx, Karl (1953) Grundrisse der Kritik der politischen Ökonomie (Rohentwurf). Elementos fundamentales para la crítica de la economía política. (Borrador) 1857-1858.

- Marcuse, Herbert, Sobre Marx y Heidegger: escritos filosóficos (1932 -1933). Edición, Madrid: Biblioteca Nueva, 2016.

- Ravelo Cabrera, Paul, "Marx, Derrida, el gesto políico y la supercapitalización mundial", Revista de filosofía (San José), Costa Rica, Clase, Vol 40, N. 102.

- Alexander Kluge, Nachrichten aus der ideologischen AntikeMarx/Eisenstein/Das Kapital (Noticias de la antigüedad ideológica Marx/Eisenstein/El Capital) Alexander Kluge, Alemania. VOSE 570' (9h 30') DigiBeta, 2008.

- Jameson, F. (2009). "Marx y el montaje, Sobre Noticias de la antigüedad ideológica de Alexander Kluge", la Fuga, Revista de Cine.

- Slavoj Zizek: Interpelación, ideología y fantasía. Zizek, Slavoj. "La falta en el otro" (parte segunda) y El sujeto (parte tercera). En: El sublime objeto de la ideología. México DF: Siglo XXI, 1999. 